\title{
Evidence-based and pragmatic steps for pharmacists to improve patient adherence
}

This article was published in the following Dove Press journal:

Integrated Pharmacy Research and Practice

14 May 2015

Number of times this article has been viewed

\section{Tommy Eriksson}

Department of Clinical Pharmacology, Institution of Laboratory Medicine Lund, Lund University, Lund, Sweden
Correspondence: Tommy Eriksson Department of Clinical Pharmacology, Institution of Laboratory Medicine Lund, Lund University, Skåne University Hospital, SE-22I 85 Lund, Sweden Email tommy.eriksson@med.lu.se
Abstract: All strategies and tools to improve the potential outcomes of medications therapy are a waste of time if the clients do not take their medication as prescribed. The aim of this paper is to help pharmacists to help their clients to improve outcomes of medicines based on improving their compliance to evidence-based pharmacotherapy. To reach a good compliance (result), you have to have agreement and concordance (method) between the practitioner and the client. Barriers and strategies for this, including identifying compliance problems and reasons for it, methods for improving information and communication, the client's participation, and responsibility for their own health, are presented mainly based on Cochrane reviews. Also some general pragmatic suggestions for how pharmacists can assist their clients the best are given.

Keywords: patient adherence, evidence-based medicine, evidence-based pharmacy, Cochrane reviews

\section{Introduction}

In the European Journal of Hospital Pharmacy, I and two colleagues have published several papers on evidence-based pharmacy. One of them is "How to best practice evidence-based pharmacy with your available resources."' The aim of that publication is to help pharmacists working in different settings to identify, evaluate, and use their own evidence-based sources for improving outcome of client care. One of the two key principles of evidence-based medicine is that the evidence alone is never sufficient to make a clinical decision. Practitioners require expertise in interpreting the patient problems (clinical, economic, and humanistic) and in identifying the evidence for optimal patient treatment. These considerations, however, are not enough. Evidence-based medicine requires the incorporation of the client's values and preferences into decision making so that they can agree on the most important objectives and also take active part in the follow-up on effects. This is important since not only adherence to medications might improve the benefits of prescribed medications but good adherence can also increase their adverse effects. Therefore, it is important to first assess whether the treatment is evidence based, including patient individualized, and thereafter to apply a patient-centered approach to make the patient follow the agreed treatment plan. It is also important to continuously address potential problems in the client's use of medication as presented in Table 1. Several of those can result in poor compliance and have to be carefully assessed and solved in agreement with the patient to reconcile and optimize treatment. submit your manuscript | www.dovepress.com

Dovepress

http://dx.doi.org// 0.2147/IPRP.S83030
Integrated Pharmacy Research and Practice 2015:4 13-19 13

(c) (i) (5) 2015 Eriksson. This work is published by Dove Medical Press Limited, and licensed under Creative Commons Attribution - Non Commercial (unported, v3.0) License. The full terms of the License are available at http://creativecommons.org/licenses/by-nc/3.0/. Non-commercial uses of the work are permitted without any further permission from Dove Medical Press Limited, provided the work is properly attributed. Permissions beyond the scope of the License are administered by Dove Medical Press Limited. Information on how to request permission may be found at: http://www.dovepress.com/permissions.php 


\section{Definitions}

Adherence can be defined as the extent (in percent) to which patients follow the instructions they are given for prescribed treatments. ${ }^{2}$ The term, adherence, is intended to be non-judgmental, a statement of fact rather than of blame of the patient, prescriber, or treatment. As stated by McDonald et al in 2002, compliance and concordance are synonyms for adherence. ${ }^{3}$ According to a later Cochrane review by Haynes et al, in which McDonald is the coauthor, it is stated that "Adherence is not the same as concordance, which includes a consensual agreement about treatment taking established between patient and practitioner." 2 Very recently, the Cochrane review was updated without describing or discussing definitions. ${ }^{4}$ In my mind, concordance is a method to improve adherence, ie, compliance. If patient-practitioner concordance (method) is poor, the adherence (result) is probably also poor. This is illustrated in Figure 1.

\section{Importance}

In Cochrane reviews, it was concluded that people who are prescribed self-administered medications typically take less than half the prescribed doses. ${ }^{2,4}$ Good adherence is associated with positive health outcome. In a meta-analysis including 21 studies and 46,847 patients, Simpson et al studied the association between adherence to medications and death. ${ }^{5}$ Odds ratio for good vs poor adherence was $0.56(95 \%$ confidence interval $0.50-0.63)$, for placebo 0.56 (0.43-0.74) and for beneficial medication 0.55 (0.49-0.62). Good vs poor adherence for harmful treatment was 2.90 (1.04-8.11). High adherence was also associated with lower risk of death and hospital admissions in patients with heart failure, regardless of treatment with candesartan or placebo in a very large double-blind randomized controlled trial study $\left(7,600\right.$ patients, $>3$ years). ${ }^{6}$ Also in a large cohort study (31,400 patients, 4 years), it was shown that adherence to evidence-based treatment (statins and beta-blocker) but not to calcium channel blocker reduced mortality after acute myocardial infarction. ${ }^{7}$ In the latter study, the authors conclude that "The long-term survival advantages associated with improved drug adherence after AMI appear to be

Table I Examples of follow-up to improve outcomes of treatment Reduction of symptom and signs for which the treatment was initiated, examinations, lab-tests, and general and specific scoring schemes Information and communication problems Potential adverse effects from the treatment Practical problems related to intake and use Problems related to behavior and attitudes

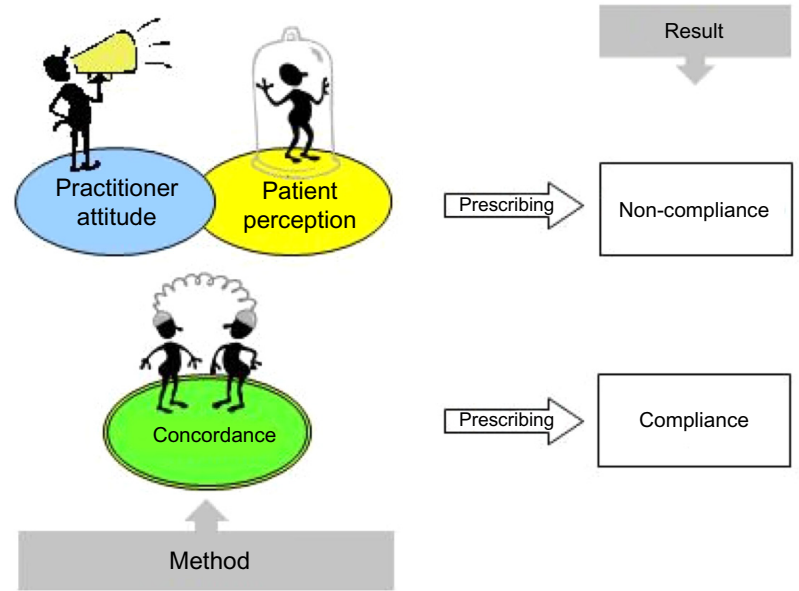

Figure I Brief description on concordance as a method for improving patient compliance (result) to prescribed medications.

class-specific, suggesting that adherence outcome benefits are mediated by drug effects and do not merely reflect an epiphenomenon of 'healthy adherer' behavioral attributes." The World Health Organization (WHO) concludes that "Increasing the effectiveness of adherence interventions may have a far greater impact on the health of the population than any improvement in specific medical treatments." Table 2 gives take home messages from the publication.

\section{Strategies for improvement}

The Cochrane Consumers and Communication Review Group has published several reviews on topics related to improvement strategies. In one of these, it was concluded that "For short-term treatments several quite simple interventions increased adherence and improved patient outcomes, but the effects were inconsistent from study to study with less than half of studies showing benefits. Current methods of improving adherence for chronic health problems are mostly complex and not very effective, so that the full benefits of treatment cannot be realized." 2 The same Cochrane group performed, and the new review 6 years later included 109 new randomized controlled trials. ${ }^{4}$ Their conclusion was similar, but they also stated that compared to the previous review, they "report a lack of convincing evidence also specifically among the studies with the lowest risk of bias."

Another Cochrane review summarized systematic reviews on interventions to improve safe and effective medicines used by consumers. . They stated that "no single strategy improved all medicines-use outcomes across all diseases, populations or settings. Medicines self-monitoring and self-management programs improved the outcome, while 
Table 2 Take home messages from WHO

Poor adherence to treatment of chronic diseases is a worldwide problem of striking magnitude

The impact of poor adherence grows as the burden of chronic diseases grows worldwide

The consequences of poor adherence to long-term therapies are poor health outcomes and increased health care costs

Improving adherence also enhances patients' safety

Adherence is an important modifier of health system effectiveness

"Increasing the effectiveness of adherence interventions may have a far greater impact on the health of the population than any improvement in specific medical treatments"

Health systems must evolve to meet new challenges

Patients need to be supported, not blamed

Adherence is simultaneously influenced by several factors

Patient-tailored interventions are required

Adherence is a dynamic process that needs to be followed up

Health professionals need to be trained in adherence

Family, community, and patients' organizations: a key factor for success

in improving adherence

A multidisciplinary approach toward adherence is needed

Notes: Data from Adherence to long-term therapies: evidence for action World Health Organisation; 2003. Available from: http://whalibdoc.who.int/ publications/2003/9241545992.pdf. Assessed February 17, 2015. ${ }^{8}$

Abbreviation: WHO, World Health Organization.

simplified dosing regimens and directly involving pharmacists in medicines management (eg, medicines reviews) appear promising." Table 3 summarizes their findings related to patient adherence.
As stated by all reports and reviews, adherence is simultaneously influenced by several factors. Some of the most important ones are given in Figure 2. Again strategies must focus on patient, practitioner, and also health system-related factors, resulting in poor adherence.

As presented in the Cochrane reviews, a majority of interventions have been designed to resolve one or a few problems assumed to influence adherence. ${ }^{2,4}$ However, there are many dimensions to adherence behavior, and according to a model suggested by the WHO, an intervention to improve this behavior needs to include technical, behavioral, cognitive, and emotional tools and always depends on the character of the specific problem. ${ }^{8}$ A Cochrane review of interventions to improve adherence to lipid-lowering drugs also concludes that reminders, simplified drug regimes, increased patient centeredness, and emphasis on the patient's perspective all show promising results. ${ }^{10}$ Communication problems in health care may arise as a result of health care providers focusing on diseases and their management, rather than people, their lives, and their health problems. Patient-centered approaches to care delivery in the patient encounter are increasingly advocated by consumers and clinicians and incorporated into training for health care providers. ${ }^{11}$ Interventions are evaluated as effective across studies in transferring patientcentered skills to providers. However, the effects on patient

Table 3 Selected statements and evidence ratings of intervention related to patient adherence

\begin{tabular}{|c|c|}
\hline Statement & Evidence level* \\
\hline Strategies that focus on the acquisition of skills and competencies to improve adherence and clinical outcomes & Some/mixed \\
\hline Provision of counseling of patients and/or physicians by pharmacists to improve adherence & Some \\
\hline Provision of more intensive patient care & Insufficient \\
\hline \multicolumn{2}{|l|}{ Provision of training by pharmacists: } \\
\hline To improve adherence & Insufficient \\
\hline To improve knowledge and medicines use & Some \\
\hline Self-administration programs to improve medicines adherence, knowledge, errors, or satisfaction (generally ineffective) & Insufficient \\
\hline \multicolumn{2}{|l|}{ Overall, interventions that provide information or education as a single component may be ineffective to improve adherence } \\
\hline \multicolumn{2}{|l|}{ or clinical outcomes } \\
\hline When used in combination with other interventions, such as self-management skills training, counseling, or as part & Some/mixed \\
\hline \multicolumn{2}{|l|}{ of pharmacist-delivered packages of care, there is evidence that education or information may improve adherence } \\
\hline \multicolumn{2}{|l|}{ and other outcomes such as clinical outcomes and knowledge } \\
\hline $\begin{array}{l}\text { Simple interventions for short-term treatments and complex interventions for long-term treatments improve adherence } \\
\text { and clinical outcomes }\end{array}$ & Some \\
\hline Self-monitoring or self-management programs improve medicines use, adherence, and clinical outcomes & Sufficient \\
\hline Simplified dosing regimens are generally effective in improving medicines adherence & Some \\
\hline Reminders, cues and/or organizers, reminder packaging, and material incentives are effective to improve medicines adherence & Some/mixed \\
\hline Pharmacists disease education and medicines management are effective to improve adherence, numbers of prescribed & Some/mixed \\
\hline \multicolumn{2}{|l|}{ medicines, and clinical outcomes } \\
\hline \multicolumn{2}{|l|}{ In older people, pharmacist-delivered interventions: } \\
\hline \multirow{2}{*}{$\begin{array}{l}\text { To optimize medicine } \\
\text { medicines) }\end{array}$} & Some \\
\hline & Some/mixed \\
\hline For other outcomes, including adverse events & Insufficient \\
\hline
\end{tabular}

Notes: *Ratings: Sufficient, some, insufficient, and insufficient (to determine) evidence. Based on a rating scheme to help synthesize and rate the evidence across systematic reviews where interventions are complex and diverse. ${ }^{9}$ Data from Ryan et al. ${ }^{9}$ 


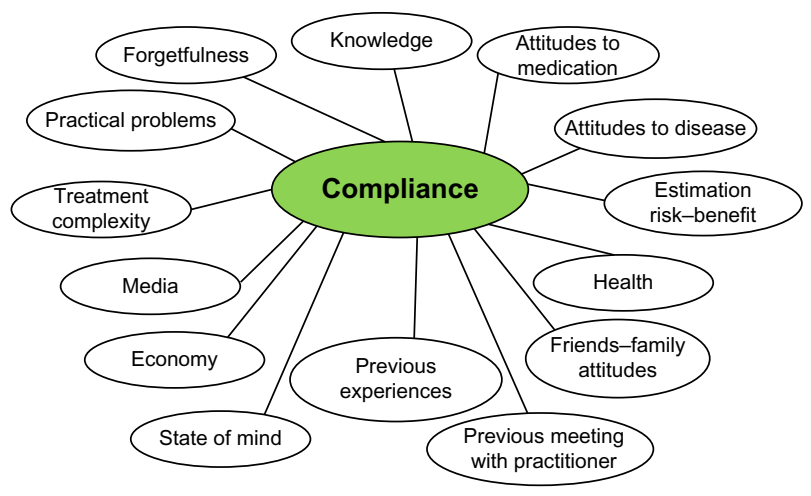

Figure $\mathbf{2}$ Some factors associated with patient adherence to medications.

satisfaction, health behavior, and health status are mixed. There is some indication that complex interventions directed at providers and patients that include condition-specific educational materials have beneficial effects on health behavior and health status outcomes.

Shared decision making (SDM) is a process by which a health care choice is made jointly by the practitioner and the patient (ie, concordance) and is said to be the crux of patient-centered care, including the right of patients to be involved in decisions concerning their health. ${ }^{12}$ However, the Cochrane review did not allow firm conclusions about the most effective types of intervention for increasing health care professionals' adoption of SDM. It states that health care professional training may be important, as may be the implementation of patient-mediated interventions such as decision aids.

\section{Unintentional and intentional non-compliance}

Basically, patient non-adherence can be unintentional or intentional. In both cases, but especially in the intentional, the motivation of the patient is very important and described below. Unintentional non-compliance could be related to forgetfulness and the prescribed number of doses per day is inversely related to compliance, and less-frequent dosing regimens have been shown to result in better compliance across a variety of therapeutic classes. ${ }^{13}$ Other ways for improvement can be to better incorporate the medicine intake to daily routines, use of intake, and reminder aids of different kinds adapted to the patient's needs. The patient might also need aids to open containers, use eye drops etcetera. Asking the patient all of these questions is very important to assist for better adherence.

New information technologies have the potential to assist the practitioner and patient to improve adherence. However, a Cochrane review stated that it was not possible to adequately assess the effect of email for clinical communication between patients/caregivers and health care professionals. ${ }^{14}$ Interactive health communication applications appear to have largely positive effects on users, in that users tend to become more knowledgeable, feel better socially supported, and may have improved behavioral and clinical outcomes compared to non-users. ${ }^{15}$

\section{Improving information and communication}

The basis for patient-centered care, SDM, and concordance is information on benefits and risks for different treatment options. It is important to be aware of the fact that the presentation of efficacy (benefit and harm) data influences patient preferences for treatment options. You should use verbal, numerical, and or graphical presentations, but it is not easy to communicate this adapted to each patient. In a Cochrane review, it was shown that decision aids with explicit value clarification exercises improve informed value-based choices; decision aids appear to have a positive effect on patient-practitioner communication and decision aids have a variable effect on length of consultation; decision aids increase people's involvement and improve knowledge and realistic perception of outcomes. ${ }^{16}$ Decision aids are stated to have a variable effect on choices and have no apparent adverse effects on health outcomes or satisfaction. The effects on adherence with the chosen option, patient-practitioner communication, cost-effectiveness, and use with developing and/or lower literacy populations need further evaluation. It is also stated that little is known about the degree of detail that decision aids need in order to have positive effects on attributes of the decision or decision-making process. Some aspects of this were also evaluated in another Cochrane review (Table 3 ). ${ }^{9}$

Be aware that verbal descriptions like common, seldom, etcetera are simple and familiar but very unclear and are perceived differently. Based on a Cochrane review, it was stated that natural frequencies are probably better understood than percentages in the context of diagnostic or screening tests. For communicating risk reductions and relative risk reduction, compared with absolute risk reduction and number needed to treat, may be perceived to be larger and is more likely to be persuasive. ${ }^{17}$ However, it is uncertain whether presenting relative risk reduction is likely to help people make decisions most consistent with their own values, and in fact, it could lead to misinterpretation. Table 4 expresses different ways to present the same figures. 
Efficacy data can also be presented using graphics, and this can improve the patient understanding. ${ }^{18}$ The more they are interactive and individually adapted to the patient's needs, the better. Pictograms are perhaps the overall best format; histogram is also good, vertical better than horizontal. Tables make it easy to see the numbers right, but it is not easy to interpret key messages. An example of a pictogram is given in Figure 3 and also at http://www.nntonline.net/visualrx/ you can prepare your own pictogram.

\section{Beliefs, behavior, and concordance methods}

In a Cochrane review, ${ }^{10}$ the adherence interventions for hypertension showing positive effects on both adherence measures and clinical outcomes included repeat contacts with patients. They used nurses or pharmacists who reinforced adherence, asked questions, educated patients, and changed doses when needed. More recent findings from studies taking account of the complexity of adherence issues as well as the need for repeated contacts, conducted in the same patient group, show promising results though not reporting results of both adherence and clinical outcomes. Some aspects of this were also evaluated in another Cochrane review (Table 3). ${ }^{8}$

The effect of a pharmacist intervention in secondary care has been studied. ${ }^{19}$ The Beliefs about Medicines Questionnaire (BMQ) - specific was used as a tool for the discussion with patient and collaboration between hospital, pharmacies, and primary care. BMQ - specific has been found to correlate with adherence. ${ }^{20,21}$ Factors negatively influencing beliefs have been found to be: the perception that the provider did not listen carefully to the patient, depression, hospital discharge with greater than seven medications, and not receiving a medication list/

Table 4 Different ways to present the same treatment benefit

Frequency

16/100 people with NRT stop smoking, compared with 10/100 people receiving a placebo

Probability

The probability of a person to stop smoking with NRT is $16 \%$.

Absolute risk difference

NRT increases the chance of quitting smoking by $6 \%$

Relative risk

NRT offers a $70 \%$ greater chance of quitting smoking NNT

For every 18 people treated with NRT, only one person successfully quit smoking compared with placebo

Adapted to the patient

Among 100 people like you, 16 successfully quit smoking with NRT, compared to ten people who successfully quit without using any substitutes

Abbreviations: NRT, nicotine replacement therapy; NNT, number needed to treat. instructions at discharge. With the BMQ - specific, patients can be categorized according to the Necessity-Concerns Framework into four groups. ${ }^{22,23}$ The different groups, termed accepting, ambivalent, neutral/indifferent, and skeptical, have been found to have different adherence behaviors. Accepting patients report higher adherence than all the other groups, ambivalent patients report lower adherence than accepting but higher than neutral and skeptical patients, and no significant difference can be found between neutral and skeptical patients.

I have been responsible for the development and research on the Lund Integrated Medicines Management model. ${ }^{24}$ It includes a systematic approach for medication reconciliation at admission to hospital, including a list of actual prescribed and used medications. The Morisky compliance assessment scale $^{25}$ and BMQ - specific ${ }^{20}$ are used to further assess compliance and behavior if needed. ${ }^{26}$

Patient-centered care including SDM (described in this paper as concordance methodology) is important, especially for patient with negative attitudes to medications, ie, negative score on the BMQ - specific. Agreement and motivation with the patients to take evidence-based medications is not easy. Significant effects have been shown on different areas of health behavior change, including medication adherence, with motivational interviewing (MI). ${ }^{27} \mathrm{MI}$ is a patient-centered approach feasible for the problem elucidation, to find the individual resources, and for the joined goal setting, all aspects that are needed to influence the complex behavior of medication adherence. MI can be used to find the patient's specific barriers for adherence and their individual solutions for both unintentional and intentional non-adherence. MI conceptualizes that motivation can fluctuate and can be influenced to change in a specific direction. Lack of motivation (or resistance to change) is seen as something that is open to change. The main focus of MI is facilitating behavior change by helping people to explore and resolve their ambivalence about behavior change. MI differs from patient-centered approaches in that it is directive. MI has a clear goal of exploring the subject's ambivalence so that the patient is more likely to choose to change the behavior in the desired direction. The four guiding principles are: expressing empathy, developing discrepancy, rolling with resistance, and supporting self-efficacy. The patient is the expert and decides on his/her objectives.

\section{Conclusion}

In this paper, I have focused on patient- and practitionerrelated factors for improving adherence. I have not focused much on poor adherence related to health care systems since it 


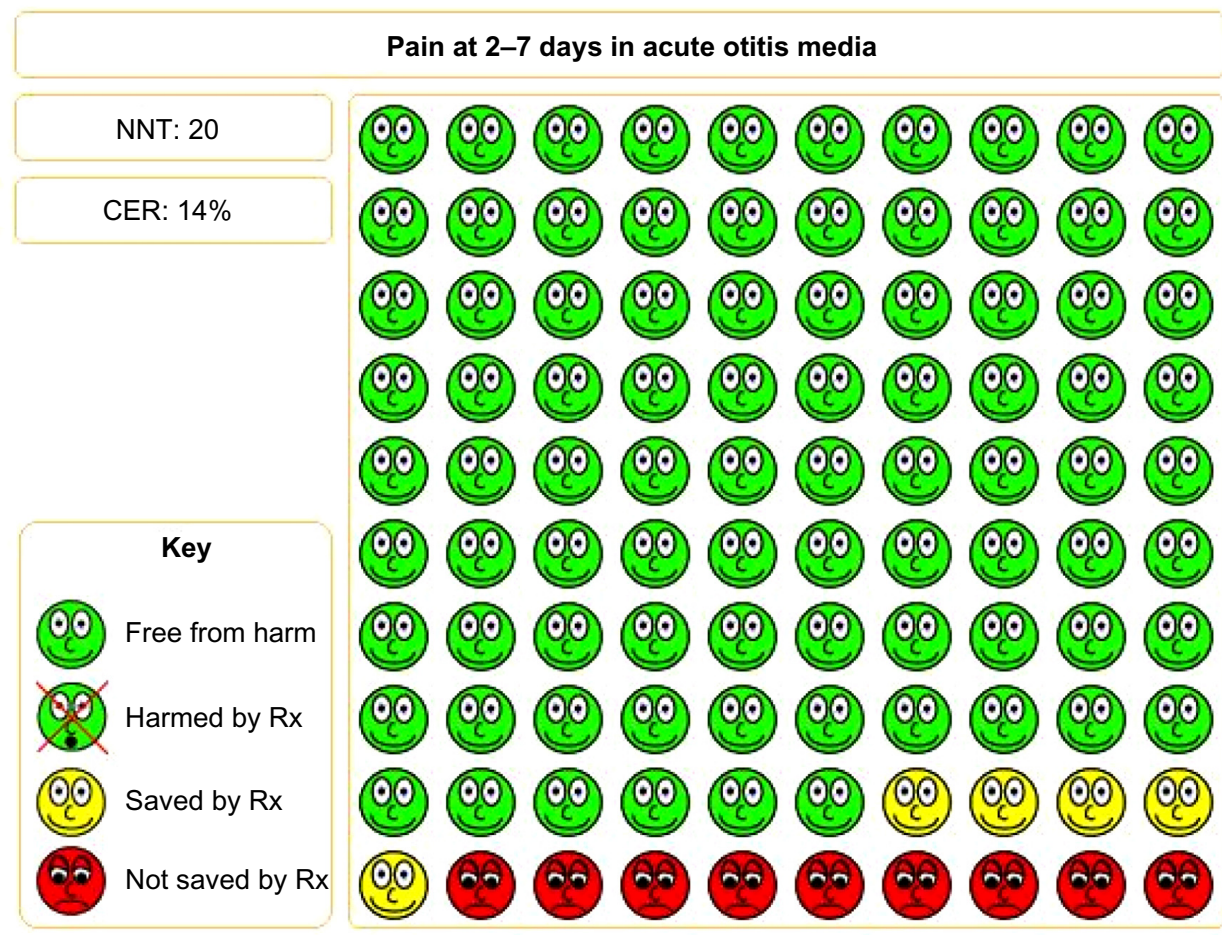

Figure 3 An example of a usable pictogram.

Abbreviations: CER, central effect ratio; NNT, number needed to treat; Rx, prescription medication.

is very complex and diversified. However, you have to realize the problems connected to it and be systematic, pragmatic, flexible, and responsible, as described patient adherence to evidence-based prescription is crucial for evidence-based pharmacy practice. In Table 5, a summary of important steps is presented.

As described, there is not much evidence for all the steps needed to overcome barriers, so you have to be pragmatic.

Table 5 Checklist for assessing and assisting your client to improved outcome of pharmacotherapy

\begin{tabular}{|c|c|}
\hline Action & Tool \\
\hline $\begin{array}{l}\text { Identify all actual prescribed medications and patient's } \\
\text { needs } \\
\text { Identify what medications the client takes } \\
\text { Identify the client's problems with their medications, } \\
\text { ie, handling, effects/adverse effect } \\
\text { Identify additional sources for potential barriers to } \\
\text { non-compliance, ie, beliefs and attitudes }\end{array}$ & Eriksson ${ }^{24}$ \\
\hline $\begin{array}{l}\text { Identify therapies not based on best evidence } \\
\text { Identify the most important medications based on } \\
\text { the client's diseases and symptoms }\end{array}$ & Eriksson et al' \\
\hline $\begin{array}{l}\text { Give information on benefits and risk adapted to the } \\
\text { client (verbal, numerical, graphs) }\end{array}$ & $\begin{array}{l}\text { This } \\
\text { publication }\end{array}$ \\
\hline Help the client with practical problems & \\
\hline $\begin{array}{l}\text { Start a more deepened concordance strategy, including } \\
\text { a patient-centered approach and shared decision making } \\
\text { Follow-up the consultation }\end{array}$ & \\
\hline
\end{tabular}

Epstein et al suggests a stepwise approach for the practitioners overall philosophy ${ }^{28}$ :

Step 1, understand the patient's (and family members') experience and expectations;

Step 2, build partnership;

Step 3, provide evidence, including a balanced discussion of uncertainties;

Step 4, present recommendations; and

Step 5, check for understanding and agreement.

If the condition or symptom is not acute, go slow if the steps cannot be completed in the first consultation. Be flexible to use different approaches for more easy adaptation to the different ways in which people learn or process information. Be open to reconsidering medical decisions and leave the door open for future discussions and to changing patient needs.

\section{Disclosure}

The author has no conflicts of interest in this work.

\section{References}

1. Eriksson T, Lu H, Wiffen P. Chapter 6: how to best practice evidencebased pharmacy with your available resources? Eur J Hosp Pharm. 2014;21:194-201. doi: 10.1136/ejhpharm-2014-000497.

2. Haynes RB, Ackloo E, Sahota N, McDonald HP, Yao X. Interventions for enhancing medication adherence. Cochrane Database Syst Rev. 2008;2:CD000011. doi: 10.1002/14651858.CD000011.pub3. 
3. McDonald HP, Garg AX, Haynes R. Interventions to enhance patient adherence to medication prescriptions: scientific review. JAMA. 2002;288:2868-2879.

4. Nieuwlaat R, Wilczynski N, Navarro T, et al. Interventions for enhancing medication adherence. Cochrane Database Syst Rev. 2014;11:CD000011. doi: 10.1002/14651858.CD000011.pub4.

5. Simpson SH, Eurich DT, Majumdar SR, et al. A meta-analysis of the association between adherence to drug therapy and mortality. BMJ. 2006;333:15-18.

6. Granger BB, Swedberg K, Ekman I, et al; CHARM investigators. Adherence to candesartan and placebo and outcomes in chronic heart failure. Lancet. 2005;366:2005-2011.

7. Rasmussen JN, Chong A, Alter DA. Relationship between adherence to evidence-based pharmacotherapy and long term mortality after acute myocardial infarction. JAMA. 2007;297:177-186.

8. Adherence to long-term therapies: evidence for action. World Health Organisation; 2003. Available from: http://whqlibdoc.who.int/ publications/2003/9241545992.pdf. Assessed February 17, 2015.

9. Ryan R, Santesso N, Lowe D, et al. Interventions to improve. safe and effective medicines use by consumers: an overview of systematic reviews. Cochrane Database Syst Rev. 2014;4:CD007768. doi: 10.1002/14651858.CD007768.pub3.

10. Schedlbauer A, Davies P, Fahey T. Interventions to improve adherence to lipid lowering medication. Cochrane Database Syst Rev. 2010;3:CD004371. doi: 10.1002/14651858.CD004371.pub3.

11. Dwamena F, Holmes-Rovner M, Gaulden CM, et al. Interventions for providers to promote a patient-centered approach in clinical consultations. Cochrane Database Syst Rev. 2012;12:CD003267. doi 10.1002/14651858.CD003267.pub2.

12. Légaré F, Ratté S, Stacey D, et al. Interventions for improving the adoption of shared decision making by healthcare professionals. Cochrane Database Syst Rev. 2010;5:CD006732. doi: 10.1002/14651858. CD006732.pub2.

13. Claxton AJ, Cramer J, Courtney P. A systematic review of the associations between dose regimens and medication compliance. Clin Ther. 2001;23:1296-1310.

14. Atherton H, Sawmynaden P, Sheikh A, Majeed A, Car J. Email for clinical communication between patients/caregivers and healthcare professionals. Cochrane Database Syst Rev. 2012;11:CD007978. doi 10.1002/14651858.CD007978.pub2.

15. Murray E, Burns J, See Tai S, Lai R, Nazareth I. Interactive health communication applications for people with chronic disease. Cochrane Database Syst Rev. 2005;4:CD004274. doi: 10.1002/14651858. CD004274.pub4.
16. Stacey D, Bennett CL, Barry MJ, et al. Decision aids for people facing health treatment or screening decisions. Cochrane Database Syst Rev. 2011;10:CD001431. doi: 10.1002/14651858.CD001431.pub3.

17. Akl EA, Oxman AD, Herrin J, et al. Using alternative statistical formats for presenting risks and risk reductions. Cochrane Database Syst Rev. 2011;3:CD006776. doi: 10.1002/14651858.CD006776.pub2.

18. Hawley S, Zikmund-Fisher B, Ubel P, Jancovic M, Lucas T, Fagerlin A. The impact of the format of graphical presentation on health-related knowledge and treatment choices. Patient Educ Couns. 2008;73: 448-455.

19. Allen LaPointe NM, Ou FS, Calvert SB, et al. Changes in beliefs about medications during long-term care for ischemic heart disease. Am Heart J. 2010;159:561-569.

20. Horne R, Weinman J. Patients' beliefs about prescribed medicines and their role in adherence to treatment in chronic physical illness. J Psychosom Res. 1999;47:555-567.

21. Berglund E, Lytsy P, Westerling R. Adherence to and beliefs in lipidlowering medical treatments: a structural equation modeling approach including the necessity-concern framework. Patient Educ Couns. 2013;91:105-112.

22. Horne R, Parham R, Driscoll R, Robinson A. Patients' attitudes to medicines and adherence to maintenance treatment in inflammatory bowel disease. Inflamm Bowel Dis. 2009;15:837-844.

23. Tibaldi G, Clatworthy J, Torchio E, Argentero P, Munizza C, Horne R. The utility of the necessity - concerns framework in explaining treatment non-adherence in four chronic illness groups in Italy. Chronic Illn. 2009;5:129-133.

24. Eriksson T. Results from a project to develop systematic patient focused clinical pharmacy services. The Lund Integrated Medicines Management (LIMM)-model. Eur J Hosp Pharm. 2014;21:121-124.

25. Morisky DE, Ang A, Krousel-Wood M, Ward HJ. Predictive validity of a medication adherence measure in an outpatient setting. $J$ Clin Hypertens (Greenwich). 2008;10:348-354.

26. Bondesson $\AA$, Hellström L, Eriksson T, Höglund P. A structured questionnaire to assess patient compliance and beliefs about medicines taking into account the ordered categorical structure of data. J Eval Clin Pract. 2009; 15:713-723.

27. Rubak S, Sandbaek A, Lauritzen T, Christensen B. Motivational interviewing: a systematic review and meta-analysis. Br J Gen Pract. 2005;55:305-312.

28. Epstein RM, Alper BS, Quill TE. Communicating evidence for participatory decision making. JAMA. 2004;291:2359-2366.

\section{Publish your work in this journal}

Integrated Pharmacy Research and Practice is an international, peer-reviewed, open access, online journal, publishing original research, reports, reviews and commentaries on all areas of academic and professional pharmacy practice. This journal aims to represent the academic output of pharmacists and pharmacy practice with particular focus on integrated care. All papers are carefully peer reviewed

\section{Dovepress}

to ensure the highest standards as well as ensuring that we are informing and stimulating pharmaceutical professionals. The manuscript management system is completely online and includes a very quick and fair peer-review system, which is all easy to use. Visit http://www.dovepress.com/testimonials.php to read real quotes from published authors. 